Check for updates

Cite this: RSC Adv., 2018, 8, 11216

Received 1st January 2018

Accepted 15th March 2018

DOI: $10.1039 / \mathrm{c} 8 \mathrm{ra00002f}$

rsc.li/rsc-advances

\section{Study of water adsorption on graphene edges}

\author{
Lijuan Jiang, (D) ab Jinlong Wang, ${ }^{a}$ Peng Liu, ${ }^{\text {*b }}$ Wei Song ${ }^{a}$ and Bingling $\mathrm{He}^{\mathrm{a}}$
}

\section{Introduction}

Graphene, a two-dimensional (2D) single layer of carbon atoms bonded in a hexagonal lattice, ${ }^{1,2}$ has attracted tremendous attention due to its excellent optical transparency, ${ }^{3}$ high electrical conductivity, ${ }^{4}$ mechanical flexibility, ${ }^{3,5}$ and strong thermal/chemical stability. ${ }^{6-9}$ Earlier studies have focused on characterizing the unusual electronic and transport properties of graphene, particularly as a massless Dirac Fermion system. ${ }^{4,10,11}$ Of the many theoretical and experimental studies of graphene, a substantial portion are devoted to the properties of graphene edges, ${ }^{2,11-13}$ whose electronic states are obviously influenced by the local geometric structure and show many unique characteristics. ${ }^{13-15}$ The adsorption at an edge can also alter their properties greatly. Small gas molecules such as $\mathrm{H}_{2} \mathrm{O}, \mathrm{H}_{2}, \mathrm{O}_{2}, \mathrm{CO}, \mathrm{NO}_{2}$, and $\mathrm{NO}$, will influence the electronic structure and other properties of graphene, ${ }^{16-26}$ the adsorption of some metal atoms such as lithium ${ }^{27}$ potassium ${ }^{28}$ have been calculated. However, there is no convenient and efficient experimental method to study the adsorption on graphene edge. Graphene edge show significant field emission (FE) ability, ${ }^{29-32}$ which can be a very suitable and simple method to study the adsorption on nanomaterial. We have studied the water adsorption on multiwalled carbon nanotube by analyzing the FE behavior at different temperature.$^{33}$ In this paper, we have studied water adsorption on graphene edge by FE method. It has been found that the water adsorption will lower the work function of graphene edge. The first principle calculation based on VASP further verified the experimental results.

${ }^{a}$ Department of Physics and Electronic Engineering, Xinxiang University, Xinxiang 453003, China

${ }^{b}$ State Key Laboratory of Low-Dimensional Quantum Physics, Department of Physics, Tsinghua-Foxconn Nanotechnology Research Center, Tsinghua University, Beijing 100084, China.E-mail: pengliu@mail.tsinghua.edu.cn

\section{Experimental results and discussion}

Graphene were prepared by the chemical method. ${ }^{34}$ Scanning electron microscopy (SEM) and Raman spectroscopy indicate that the sample is few-layer graphene. Fig. 1(a) shows a SEM image of graphene. We can find that graphene have numerous thin open edges and tips. The Raman spectrum excited by a $514 \mathrm{~nm}$ laser is shown in Fig. 1(b), the high 2D peak verifies that the sample is composed predominately by few layer graphene..$^{35}$ The graphene field emitter is fabricated by sticking them on a molybdenum wire of $0.1 \mathrm{~mm}$ diameter with organic binder, which can be thoroughly evaporated after being heated at $350{ }^{\circ} \mathrm{C}$ in air a few minutes. The $\mathrm{FE}$ experiment was conducted in a high-vacuum chamber with a base pressure of $10^{-5}$ Pa. Fig. 1(c) shows the schematic diagram of the circuit. Two metal rod electrodes were used to heat the graphene with current in the vacuum chamber. Keithley 237 high voltage source measure unit was used to supply the electric voltage, an indium tin oxide (ITO) glass anode coated with phosphor was used as anode. The distance between the anode and cathode is about $200 \mu \mathrm{m}$. Fig. 1(d) is a photo of the phosphor anode lighted by the FE of graphene cathode at $1100 \mathrm{~V}$.

Fig. 2(a) shows the $I V$ curve of the graphene at room temperature (RT). Here a DC voltage sweeping from $300 \mathrm{~V}$ to $1100 \mathrm{~V}$ was applied to the sample. It can be seen that the curves show obvious noise. The emission current is $0.2 \mu \mathrm{A}$ at $3.75 \mathrm{~V} \mathrm{\mu m}^{-1}$ and $4 \mu \mathrm{A}$ at $5.5 \mathrm{~V} \mu \mathrm{m}^{-1}$. Fig. 2(b) shows the $I V$ curve of the graphene at $1198 \mathrm{~K}$. It can be seen that the $I V$ curve is very smooth. Fig. 2(c) and (d) display the corresponding FN plots. The plot at RT show obvious noise and the plot at $1198 \mathrm{~K}$ is a smooth and straight line of multi-segment. Comparing the noise curves in Fig. 2(a) and (c) and the smooth curves in Fig. 2(b) and (d), we can know that the noise is related to the temperature. The same as previous reports, ${ }^{36}$ heating can be used as a useful method to remove adsorbents. The dwelling 

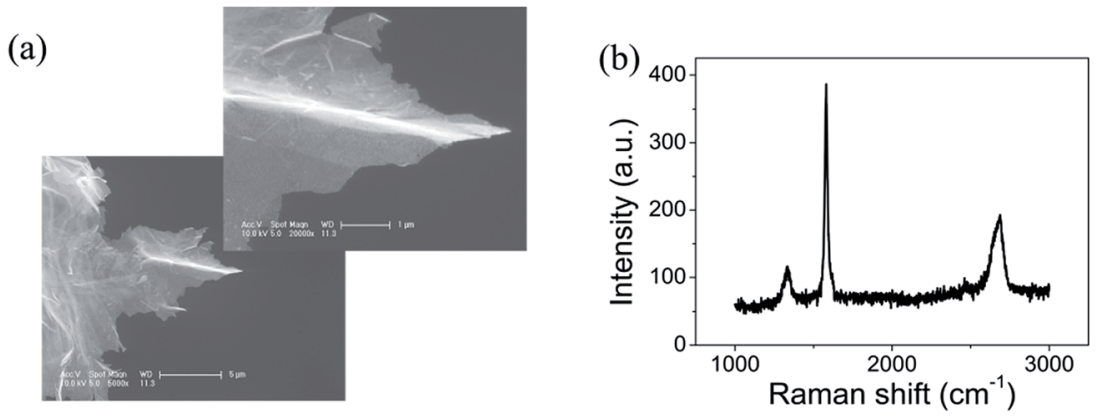

(c)

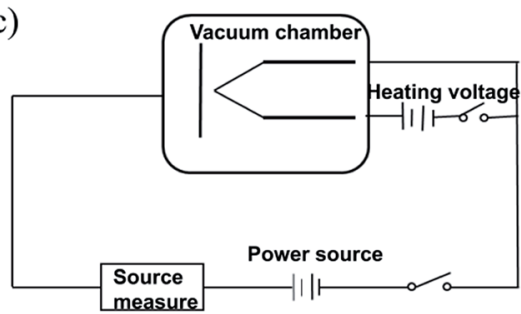

(d)

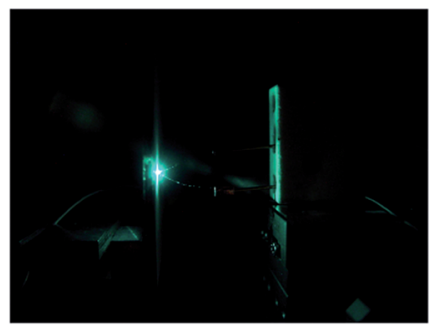

Fig. 1 (a) The scanning electron microscope (SEM) images of the graphene. The left bottom is at $5000 \times$, the right upper is at $20000 \times$. (b) Raman spectrum of graphene excited by $514 \mathrm{~nm}$ laser. (c) Schematic diagram of the circuit. (d) Photo of the phosphor anode lighted by the FE of graphene.

time of the adsorbents will be shortened at high temperature. Therefore, the FE at $1198 \mathrm{~K}$ in this experiment is determined as the intrinsic FE of graphene after the removal of adsorbents (the different segments of FN plot at $1198 \mathrm{~K}$ are caused by a small number of samples being detached during emission).

According to the FN equation, ${ }^{37}$

$$
J=\lambda_{\mathrm{M}} a \phi^{-1} E^{2} \beta^{2} \exp \left(-\frac{b \phi^{\frac{3}{2}}}{\beta E} v_{\mathrm{F}}\right)
$$

where, $J$ is the current density, $\lambda_{\mathbf{M}}$ a macroscopic preexponential correction factor, $a$ and $b$ are constants $(a=1.54$ $\left.\times 10^{-6} \mathrm{~A} \mathrm{eV} \mathrm{V}^{-2}, b=6.83 \mathrm{eV}^{-3 / 2} \mathrm{~V} \mathrm{~nm}^{-1}\right), \phi$ is the work function of the emitter (4.74 eV for graphene $\left.{ }^{33}\right), E$ is the applied electric field $^{38}(E=V / d$, where $V$ is the voltage applied between the flat cathode and the anode screen and distheir separation). $\beta$ is the local electrical field enhancement factor, $v_{\mathrm{F}}$ (correction factor) is a value of the Schottky-Nordheim barrier function $v$. The field enhancement factor $\beta$ can be calculated from the slope ' $m$ ' of the FN curves (the curves of $\ln \left(1 / V^{2}\right)$ versus $1 / V$ ), using the following equation.

$$
\beta=\frac{\left(-6.8 \times 10^{3}\right) \phi^{3 / 2}}{m}
$$

The field-enhancement factor $(\beta)$ of graphene was calculated and listed in Table 1 . The $\beta$ of graphene was 13063.81424 , $11725.88950,10676.06139$ at $830 \mathrm{~V}-947 \mathrm{~V}, 948-973 \mathrm{~V}$, 994-1052 V. There is no big difference for the $\beta$ of three segments, which is also close to the aspect ratio estimation based on the SEM image shown in Fig. 1(a). The large $\beta$ verified that the FE comes from graphene edge. Because adsorption can not change geometric structure of graphene, the $\beta$ at RT can be viewed as almost same as that at high temperature. The work function at RT calculated was 3.29 through solving eqn (2) based on $\beta$ and the slope of FN plot at RT. The substituted $\beta$ was the average value of three segments at high temperature. The work function at RT was small than this calculated by the Zhu $\mathrm{F} .{ }^{33}$ This implies that adsorption can lower the work function of graphene edge.

To further prove the influence of adsorption on the graphene, the FE current changes as the temperature switches between RT and $1198 \mathrm{~K}$ is shown in Fig. 3. It can be seen that the FE current decreases after heating to the higher temperature $1198 \mathrm{~K}$, and the FE current will increase after stopping the heating. It indicates that the work function with adsorption is smaller than that at RT. It also shows that the noise of the FE current during heating is significantly lower than that at RT. We select the time range from $1018 \mathrm{~s}$ to $1107 \mathrm{~s}$, the noise of the FE current without heating was calculated to be about $22.8 \%$. At the time range from $1111 \mathrm{~s}$ to $1154 \mathrm{~s}$, the noise of the FE current at high temperature was calculated to be about $8.99 \%$, this further evidence that the FE of the graphene at RT is influenced by the adsorption. ${ }^{36,39}$

To ascertain the kind of adsorbates which have influence the FE of graphene, we have carried out an analysis of the adsorbent species of residual gas spectra in the vacuum chamber. Fig. 4 shows the 12 main species in the vacuum chamber. It can be seen that $\mathrm{H}_{2} \mathrm{O}, \mathrm{H}_{2}$, and $\mathrm{N}_{2}$ are the most principal species. $\mathrm{H}_{2}$ and $\mathrm{N}_{2}$ are nonpolar molecules and deemed inactive, while $\mathrm{H}_{2} \mathrm{O}$ is a polar, active molecule and has a large proportion in the residual gas, so $\mathrm{H}_{2} \mathrm{O}$ is the most likely species to influence the adsorption of graphene. 
(a)

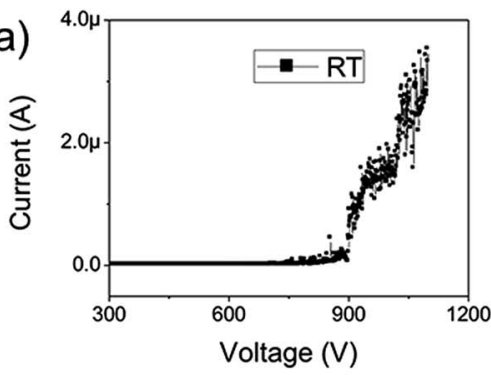

(c)

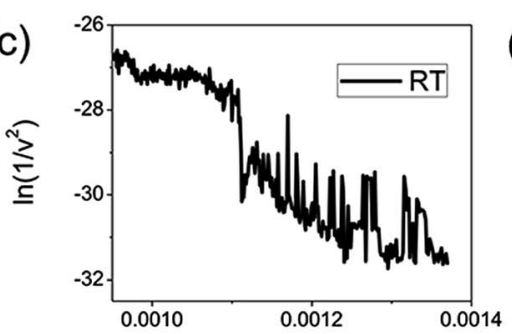

(e)

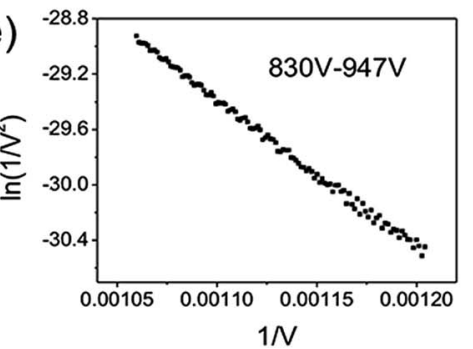

(g)

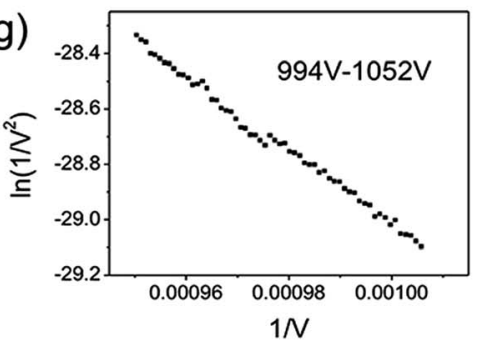

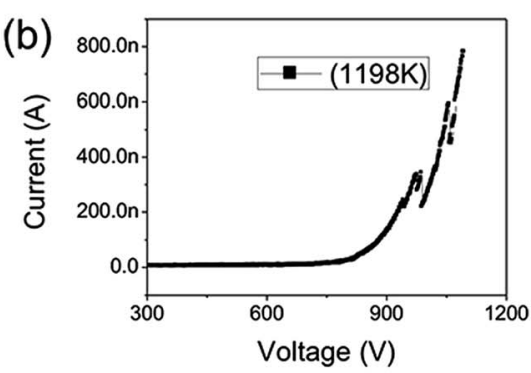

(d)

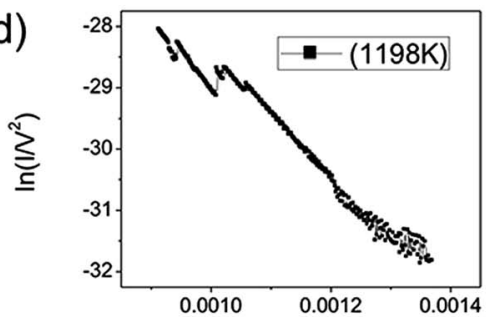

(f)

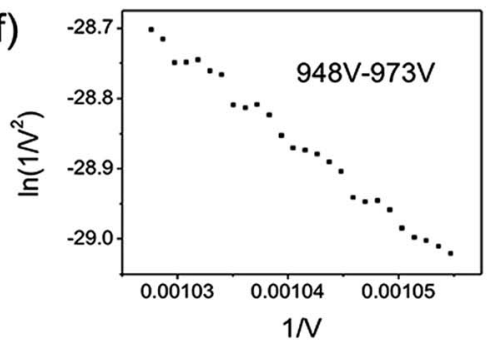

(h)

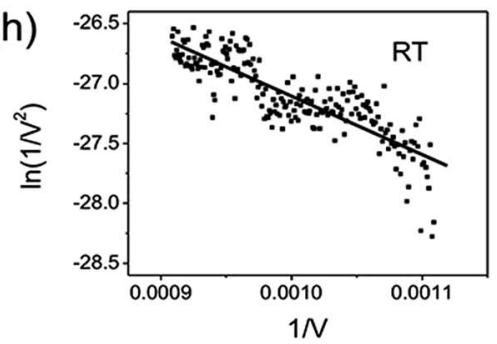

Fig. 2 (a) FE IV curves of graphene at RT. (b) FE IV curves of graphene at $1198 \mathrm{~K}$. (c) FN curves at RT. (d) FN curves at $1198 \mathrm{~K}$. (e) FN curves in the range of $830-947 \mathrm{~V}$ at $1198 \mathrm{~K}$. (f) FN curves in the range of $948-973 \mathrm{~V}$ at $1198 \mathrm{~K}$. (g) FN curves in the range of $994 \mathrm{~V}-1052 \mathrm{~V}$ at $1198 \mathrm{~K}$. (h) FN curves in the range of $900-1100 \mathrm{~V}$ at RT.

Table 1 The intercept, slope and $\beta$ of graphene at $1198 \mathrm{~K}$ and RT

\begin{tabular}{lllll}
\hline & $830-947 \mathrm{~V}$ & $948-973 \mathrm{~V}$ & $994-1052 \mathrm{~V}$ & $\mathrm{RT}$ \\
\hline Intercept & -17.56889 & -16.40583 & -15.86982 & -22.26244 \\
Slope & -10743.26837 & -11969.07597 & -13146.05238 & -4851.04459 \\
$\beta$ & 13063.81424 & 11725.88950 & 10676.06139 & 11821.92171
\end{tabular}

\section{First principle calculation of water adsorption on graphene}

Work function is the most direct parameter which can reflect the influence of the adsorption. We have calculated the work function of $\mathrm{H}_{2} \mathrm{O} /$ graphene systems with the projected augmented wave (PAW) ${ }^{40}$ formalism of DFT, as implemented in

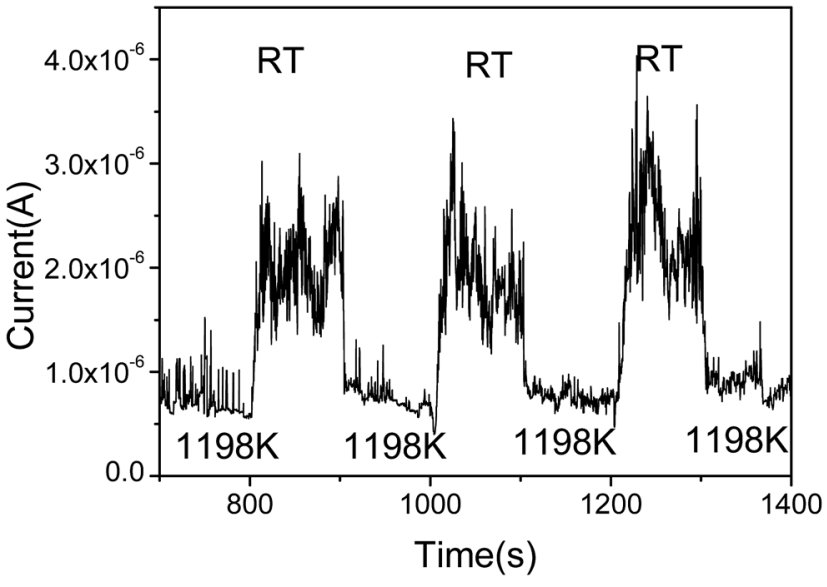

Fig. 3 FE current switches between RT and $1198 \mathrm{~K}$. 


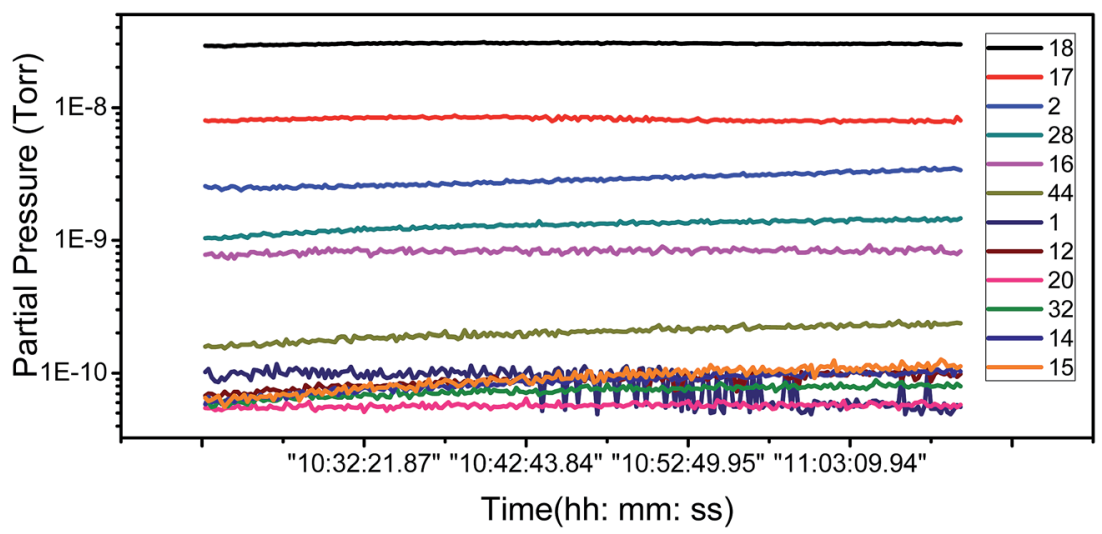

Fig. 4 Partial pressure as a function of time for the 12 main residual gases species.

the VASP. ${ }^{41}$ The adopted exchange-correlation functional is the generalized gradient approximation with the Perdew-BurkeErnzerhof (PBE) ${ }^{42}$ The cutoff energy for the plane wave basis set was taken as $400 \mathrm{eV}$. The geometry optimization of each isomer was carried out till the energy was converged to an accuracy of $10^{-4} \mathrm{eV}$. Brillouin zone integration is performed using Monkhorst-Pack grids ${ }^{43}$ for all calculations. We build three kinds of models as shown in Fig. $5(\mathrm{a}-\mathrm{c})$, the single layer graphene $(2 \times 2)$ surface slab containing $15 \AA$ vacuum layer in Fig. 5(a), five layer graphene $(2 \times 2)$ surface slab containing $15 \AA$ vacuum layer to simulate the graphite surface in Fig. 5(b), the graphene fragment in the cubic with a dimension of $25 \times 25 \times 10 \AA^{3}$ in Fig. 5 (c). The $K$-point sampling is chosen as $5 \times 5 \times 1$ and $1 \times$ $1 \times 1$ for the slab and the cubic, respectively.

We calculated the adsorption of $\mathrm{H}_{2} \mathrm{O}$ in three kinds of models as shown in Fig. 5(d)-(f). It is found that there is no chemical adsorption between $\mathrm{H}_{2} \mathrm{O}$ and the graphene as shown in Fig. 5(d). The distance between $\mathrm{H}_{2} \mathrm{O}$ and the graphene surface up to $3.70 \AA$ after relaxation. The interaction between them is only about $0.18 \mathrm{eV}$. In order to affirm our results, we (a)

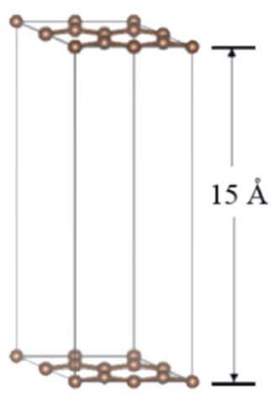

(b)

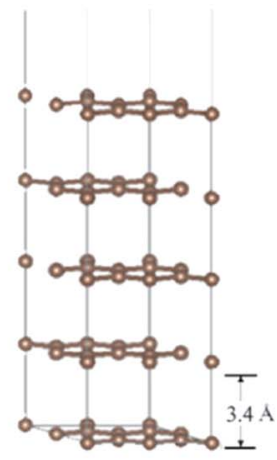

(d)

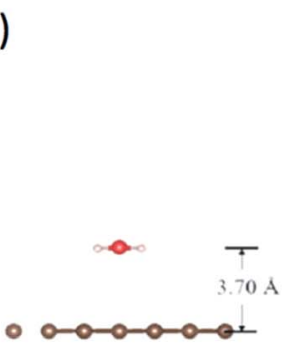

(e)

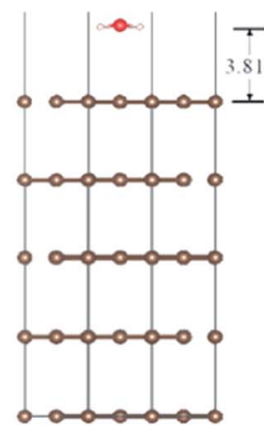

(c)

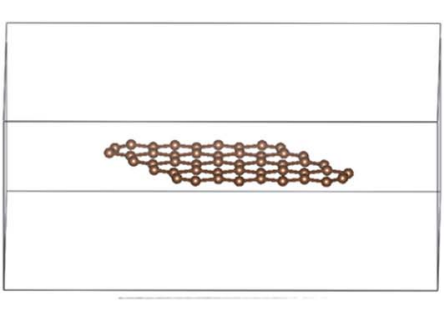

(f)
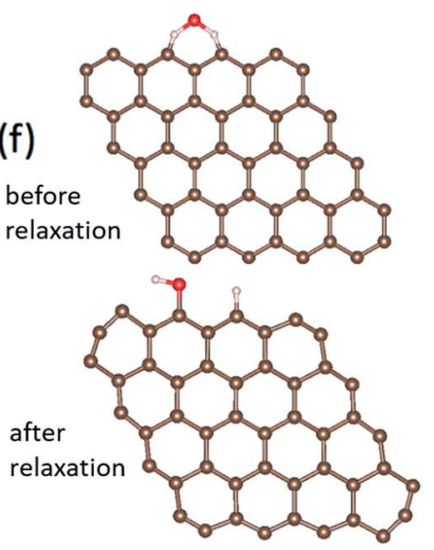

Fig. 5 (a) The single layer graphene $(2 \times 2)$ surface slab model. (b) The five layer graphene $(2 \times 2)$ surface slab model, in which the vacuum layer doesn't shown overall. (c) The graphene in the cubic. The adsorption of $\mathrm{H}_{2} \mathrm{O}$ on (d) graphene surface, (e) graphite surface with five-layer graphene and (f) at the edge of graphene before and after relaxation. 
Table 2 The work function of graphene adsorption and without $\mathrm{H}_{2} \mathrm{O}$ in the three kinds of models

\begin{tabular}{llll}
\hline Work function & Graphene slabe & 5-Layer graphene & $\begin{array}{l}\text { Graphene in } \\
\text { the cubic }\end{array}$ \\
\hline Without $\mathrm{H}_{2} \mathrm{O}$ & 4.24 & 5.00 & 5.73 \\
Exist $\mathrm{H}_{2} \mathrm{O}$ & 5.15 & 5.09 & 5.63
\end{tabular}

simulate the graphite surface with five-layer graphene as shown in Fig. 5(e). The results are similar to previous one. The distance between $\mathrm{H}_{2} \mathrm{O}$ and the surface of graphite is up to $3.81 \AA$ after relaxation. The interaction between them is $0.23 \mathrm{eV}$. Since the $\mathrm{FE}$ and adsorption/desorption happened on graphene edge in our experiment, we simulate the adsorption of $\mathrm{H}_{2} \mathrm{O}$ on the edge of graphene as shown in Fig. 5(f). It is found that the $\mathrm{H}$ atom and hydroxyl dissociate directly from $\mathrm{H}_{2} \mathrm{O}$ and adsorb at two zig-zag carbon atoms after relaxation. The adsorption energy of $\mathrm{H}$ and hydrogen bond is up to $5.93 \mathrm{eV}$, which is a strong interaction. Obviously, it is physical adsorptions for $\mathrm{H}_{2} \mathrm{O}$ on the surface of graphene and graphite, and it is chemical adsorption for $\mathrm{H}_{2} \mathrm{O}$ dissociation on the edge of graphene.

The work functions results are tabulated in Table 2. The work function without $\mathrm{H}_{2} \mathrm{O}$ are very close to the calculated work function using the average electrostatic potential of $7 \times 7$ pure grapheme $\mathrm{e}^{44}$ and the experimentally measured work function $4.45-4.74 \mathrm{eV}^{33,45-47}$ It can be found that work function for graphene slabe surface increase from $4.24 \mathrm{eV}$ to $5.15 \mathrm{eV}$ due to $\mathrm{H}_{2} \mathrm{O}$ adsorption, work function for 5-layer graphene increase from $5.00 \mathrm{eV}$ to $5.09 \mathrm{eV}$ due to $\mathrm{H}_{2} \mathrm{O}$ adsorption, while work function for graphene edge decrease from $5.73 \mathrm{eV}$ to $5.63 \mathrm{eV}$ due to $\mathrm{H}_{2} \mathrm{O}$ adsorption. This is in good accordance with our experimental results that the $\mathrm{FE}$ comes from graphene edge and the $\mathrm{FE}$ current change with the adsorption/desorption.

\section{Conclusions}

In summary, the water adsorption on graphene edge has been studied. It was found that the adsorption induced the deviation from the FN model at RT. After removing the adsorbates by heating, the intrinsic FE of graphene edge follows the FN model very well. Water is speculated as the most responsible gas specie. The work function of graphene with $\mathrm{H}_{2} \mathrm{O}$ has calculated by VASP. The calculated results show that the water adsorption will lower the work function of graphene edge, while increase the work function of graphene surface. This is in good accordance with the experimental results.

\section{Conflicts of interest}

There are no conflicts to declare.

\section{Acknowledgements}

This work is financed by the NSFC (grant No. 51672152), the Innovation Talents Program of Science and Technology of Institution of Higher Education of Henan Province, China
(Grant No. 14HASTIT044), and the Science and Technology Project of Henan Province, China(Ggrant No. 182102310884).

\section{References}

1 K. S. Novoselov, A. K. Geim, S. V. Morozov, D. Jiang, Y. Zhang, S. V. Dubonos, I. V. Grigorieva and A. A. Firsov, Science, 2004, 306, 666-669.

2 C. Ö. Girit, J. C. Meyer, R. Erni, M. D. Rossell, C. Kisielowski, L. Yang, C. H. Park, M. F. Crommie, M. L. S. G. Louie and A. Zettl, Science, 2009, 323, 1705-1708.

3 G. Eda, G. Fanchini and M. Chhowalla, Nat. Nanotechnol., 2008, 3, 270-274.

4 A. K. Geim and K. S. Novoselov, Nat. Mater., 2007, 6, 183-191. 5 C. G. Navarro, M. Burghard and K. Kern, Nano Lett., 2008, 8, 2045-2049.

6 A. A. Balandin, S. Ghosh, W. Bao, I. Calizo, D. Teweldebrhan, F. Miao and C. N. Lau, Nano Lett., 2008, 8, 902-907.

7 P. Blake, P. D. Brimicombe, R. R. Nair, T. J. Booth, D. Jiang, F. Schedin, L. A. Ponomarenko, S. V. Morozov, H. F. Gleeson, E. W. Hill, A. K. Geim and K. S. Novoselov, Nano Lett., 8, 1704-1708.

8 J. L. Vickery, A. J. Patil and S. Mann, Adv. Mater., 2010, 21, 2180-2184.

9 X. Wang, L. Zhi and K. Mullen, Transparent, Nano Lett., 2008, 8, 323-327.

10 A. C. Neto, F. Guinea, N. M. Peres, K. S. Novoselov and A. K. Geim, Rev. Mod. Phys., 2009, 81, 109-162.

11 B. Huang, M. Liu, N. H. Su, J. Wu, W. H. Duan, B. L. Gu and F. Liu, Phys. Rev. Lett., 2009, 102, 166404-166412.

12 K. Suenaga and M. Koshino, Nature, 2010, 468, 1088-1090.

13 Y. Kobayashi, K. I. Fukui and T. Enoki, Phys. Rev. B, 2006, 73, 125415-125422.

14 M. Fujita, K. Wakabayashi, K. Nakada and K. Kusakabe, J. Phys. Soc. Jpn., 1996, 65, 1920-1923.

15 K. Nakada, M. Fujita, G. Dresselhaus and M. S. Dresselhaus, Phys. Rev. B: Condens. Matter Mater. Phys., 1996, 54, 1795417961.

16 H. E. Romero, N. Shen, P. Joshi, H. R. Gutierrez, S. A. Tadigadapa, J. O. Sofo and P. C. Eklund, ACS Nano, 2008, 2, 2037-2044.

17 Y. Sato, K. Takai and T. Enoki, Nano Lett., 2011, 11, 34683475.

18 L. Liu, S. Ryu, M. R. Tomasik, E. Stolyarova, N. Jung, M. S. Hybertsen, M. L. Steigerwald, L. E. Brus and G. W. Flynn, Nano Lett., 2008, 8, 1965-1970.

19 R. Balog, B. Jørgensen, L.Nilsson, M. Andersen, E. Rienks, M. Bianchi, M. Fanetti, E. Lægsgaard, A. Baraldi, S. Lizzit, Z. Sljivancanin, F. Besenbacher, B. Hammer, T. G. Pedersen, P. Hofmann and L. Hornekær, Nat. Mater., 2010, 9, 315-319.

20 M. Zhou, Y. H. Lu, Y. Q. Cai, C. Zhang and Y. P. Feng, Nanotechnology, 2011, 22, 3855021-3855028.

21 F. Yavari, C. Kritzinger, C. Gaire, L. Song, H. Gulapalli, T. Borca-Tasciuc, P. M. Ajayan and N. Koratkar, Small, 2010, 6, 2535-2538. 
22 J. Moser, A. Verdaguer, D. Jiménez, A. Barreiro and A. Bachtold, Appl. Phys. Lett., 2008, 92, 1235071-1235073.

23 T. O. Wehling, K. S. Novoselov, S. V. Morozov, E. E. Vdovin, M. I. Katsnelson, A. K. Geim and A. I. Lichtenstein, Nano Lett., 2008, 8, 173-177.

24 Y. H. Lu, W. Chen, Y. P. Feng and P. M. He, J. Phys. Chem. B, 2009, 113, 2-5.

25 K. S. Subrahmanyam, P. Kumar, U. Maitra, A. Govindaraj, K. P. S. S. Hembram, U. V. Waghmare and C. N. R. Rao, Proc. Natl. Acad. Sci. U. S. A., 2011, 108, 2674-2677.

26 L. M. Kong, A. Enders, T. S. Rahman and P. A. Dowben, J. Phys.: Condens. Matter, 2014, 26, 443001-4430027.

27 C. Uthaisar, D. J. Hicks and V. Barone, Surf. Sci., 2014, 619, 105-113.

28 Y. L. Mao, W. P. Hao, X. L. Wei, J. M. Yuan and J. X. Zhong, Appl. Surf. Sci., 2013, 280, 698-704.

29 V. I. Kleshch, D. A. Bandurin, A. S. Orekhov, S. T. Purcell and A. N. Obraztsov, Appl. Surf. Sci., 2015, 357, 1967-1974.

30 Y. Gao and S. Okada, Applied Physics Express, 2017, 10, 0551041-0551044.

31 J. T. H. Tsai, T. Y. E. Chu, J. Y. Shiu and C. S. Yang, Small, 2012, 83, 3739-3745.

32 K. Nakakubo, K. Asaka, H. Nakahara and Y. Saito, Appl. Phys. Express, 2012, 5, 0551011-0551013.

33 F. Zhu, X. Y. Lin, P. Liu, K. L. Jiang, Y. Wei, Y. Wu, J. P. Wang and S. S. Fan, Nano Res., 2014, 7, 553-560.

34 Y. Hernandez, V. Nicolosi, M. Lotya, F. M. Blighe, Z. Y. Sun, S. De, I. T. McGovern, B. Holland, M. Byrne, Y. K. Gunko, J. J. Boland, P. Niraj, G. Duesberg, S. Krishnamurthy,
R. Goodhue, J. Hutchison, V. Scardaci, A. C. Ferrari and J. N. Coleman, Nat. Nanotechnol., 2008, 3, 563-568.

35 R. Saito, M. Hofmann, G. Dresselhaus, A. Jorio and M. S. Dresselhaus, Adv. Phys., 2011, 60, 488-503.

36 L. W. Swanson and A. E. Bell, Adv. Electron. Electron Phys., 1973, 32, 193-309.

37 R. H. Fowler and L. Nordheim, Proc. R. Soc. A, 1928, 119, 173181.

38 R. G. Forbes, Nanotechnology, 2012, 23, 0957061-09570612.

39 P. Liu, K. L. Jiang, Y. Wei, K. Liu, L. Liu and S. S. Fan, J. Vac.

Sci. Technol., B: Nanotechnol. Microelectron.: Mater., Process., Meas., Phenom., 2010, 28, 736-739.

40 G. Kresse and D. Joubert, Phys. Rev. B, 1999, 59, 1758-1774. 41 G. Kresse and J. Hafner, Phys. Rev. B, 1993, 47, 558-561.

42 J. P. Perdew and K. Burke, Phys. Rev. Lett., 1996, 77, 38653868.

43 H. J. Monkhorst and J. D. Pack, Phys. Rev. B, 1976, 13, 51885192.

44 M. Legesse, F. E. Mellouhi, E. T. Bentria, M. E. Madjet, T. S. Fisher, S. Kais and F. H. Alharbi, Appl. Surf. Sci., 2017, 394, 98-107.

45 K. P. Loh, Q. Bao, P. K. Ang and J. Yang, J. Mater. Chem., 2010, 20, 2277-2289.

46 S. Ryu, L. Liu, L. S. Berciaud, Y. J. Yu, H. Liu, P. Kim, G. W. Flynn and L. E. Brus, Nano Lett., 2010, 10, 4944-4951.

47 J. H. Kim, J. H. Hwang, J. Suh, S. Tongay, S. Kwon, C. C. Hwang, J. Wu and P. J. Young, Appl. Phys. Lett., 2013, 103, 1716041-1716045. 